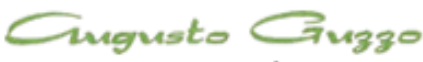

REVISTA ACADEMICA

\title{
Construção de tutoriais audiovisuais para o uso da comunidade miOne pelo idoso
}

\author{
Ana Catarina Silva Caldas' , Ana Isabel Veloso² e Maria João Antunes³ \\ Recebido em: 15/09/2014. Aprovado em: 03/11/2014. Disponibilizado em: 26/12/2014
}

1. Ana Catarina Silva Caldas é mestranda em Comunicação Multimédia do Departamento de Comunicação e Arte da Universidade de Aveiro e licenciada em Comunicação Empresarial pelo Instituto Superior de Contabilidade e Administração do Porto. e-mail: catarinacaldas@ua.pt.

2. Ana Isabel Veloso é Doutora em Ciências e Tecnologias da Comunicação da Universidade de Aveiro; é mestre em Engenharia Biomédica e licenciada em Engenharia Informática pela Universidade de Coimbra. Atualmente é docente no Departamento de Comunicação e Arte da Universidade de Aveiro e membro da direção do grupo de pesquisa Medias Digitais e Interação. Coordenadora de vários projetos de pesquisa - SEDUCE; EYE ON GAMES; EYE ON TV; Interactive Magic Places, People and Practices. As suas áreas de pesquisa são na comunicação mediada tecnologicamente, nas narrativas e jogos interativos, na interação humano-computador, para públicos específicos, crianças e idosos. É autora de inúmeras publicações nacionais e internacionais e orienta anualmente diversos alunos de Mestrado e de Doutoramento. e-mail: aiv@ua.pt.

3. Maria João Antunes Doutorou-se em Ciências e Tecnologias da Comunicação e é licenciada em Novas Tecnologias da Comunicação pela Universidade de Aveiro. Atualmente é professora auxiliar do Departamento de Comunicação e Arte da Universidade de Aveiro. É membro do comité científico grupo de pesquisa Medias Digitais e Interação e de vários projetos de investigação financiados por entidades nacionais. e-mail: mariajoao@ua.pt.

\section{Resumo}

Considerando o crescente envelhecimento populacional e a proliferação das tecnologias da informação e comunicação (TIC), a disponibilização de meios adequados ao idoso para a apreensão das TIC mostra-se como uma mais-valia. O artigo apresenta a investigação desenvolvida para conceber, planear, realizar e avaliar quatro tutoriais audiovisuais que permitam ao idoso: i) registarse na comunidade miOne; ii) conhecer a comunidade miOne, através do tutorial Visita à comunidade miOne; iii) saber usar o correio eletrónico da comunidade miOne; e iv) como conversar na comunidade miOne. A comunidade miOne foi construída com e para o idoso no âmbito do projeto SEDUCE. A investigação foi desenvolvida em três fases, cada uma delas recorrendo a uma metodologia diferente, exploratória, investigação-ação e avaliação, respetivamente. $\mathrm{Na}$ fase exploratória foram reunidos os conceitos fulcrais que permitiram desenvolver na fase de investigação-ação os guiões de voz-off, através da técnica de focus group. Os quatro tutoriais posteriormente realizados foram avaliados por um grupo de idosos, em diferentes categorias e subcategorias. Os resultados apontam para que os tutoriais audiovisuais concebidos para a comunidade miOne são percetíveis para pessoas que utilizem diariamente as TIC. Ressalvando-se que para iniciantes do uso do Computador e da Internet, que os tutoriais poderiam estar um pouco acelerados.

Palavras-chave: idoso, tutorial audiovisual, Tecnologias da Informação e Comunicação. 


\begin{abstract}
Considering the increasing of aging population and the proliferation of information and communication technologies (ICT), the available ways to the elderly on apprehension of ICT. The paper presents the research undertaken to design, plan, implement and evaluate four audiovisual tutorials that allow the elderly:1) To register in Mione community; 2) To know Mione community through the tutorial Visit Mione community; 3) To know how to use the e-mail of Mione community; and 4) How to talk in Mione community. Mione community was built with and for the elderly under the SEDUCE project. The research was developed in three phases. Each one using a different methodology: exploratory, research-action and evaluation, respectively. Exploratory the key concepts that were gathered allowed the development of a research-action stage the scripts of voice-over, through the focus group technique. The four tutorials later realized were evaluated by a group of elderly people in different categories and subcategories. The results indicate that audiovisual tutorials designed to be perceived Mione community are for people who daily use ICT. Except that for beginners to use the computer and the Internet, which the tutorials could be slightly accelerated.
\end{abstract}

Keywords: elderly, audio-visual tutorial, Information and Communication Technologies. 


\section{Introdução}

O envelhecimento é cada vez mais uma preocupação. Segundo Giannakouris (2010) 17,4\% é a proporção em 2010 para a União Europeia, de pessoas com mais de 65 anos de idade. Este valor tenderá a aumentar, de acordo com as projeções e segundo o mesmo autor, em 2030 será de 23,6\%. No contexto português, os valores são em tudo idênticos, $17,8 \%$ em 2010 e $23,3 \%$ em 2030 (Giannakouris, 2010).

Denota-se pelos dados apresentados que o envelhecimento da população é uma realidade e que acarreta consequências na sociedade que não podem ser descuradas. Segundo a Organização Mundial de Saúde (2002), as melhorias nas técnicas e cuidados de saúde têm contribuído para a melhoria de qualidade de vida, que se pode definir como a perceção que o indivíduo tem relativamente à sua posição na vida contrapondo os objetivos definidos e as preocupações. A melhoria da qualidade de vida está intrinsecamente associada ao aumento da esperança média de vida, propiciada pelo envelhecimento ativo (OMS, 2002). Caraterizando-se o envelhecimento ativo como o acesso de forma positiva à qualidade de vida e a oportunidades de saúde, participação e segurança durante $\mathrm{O}$ envelhecimento.

Outro contexto merecedor de importância para esta investigação é o das Tecnologias de Informação e Comunicação (TIC). No contexto português e de acordo com as estatísticas apresentadas pelo Instituto Nacional de Estatísticas (INE) (2012), a utilização das TIC tem vindo a aumentar, constatando-se que no ano de 2008 o uso em percentagem do computador era de 45,9\%; internet $41,9 \%$ e comércio eletrónico $6,4 \%$;

\footnotetext{
${ }^{1}$ Comunidade miOne disponível no URL www.mione.pt em 30/10/2014.
}

verificando-se que no ano de 2012 para as mesmas situações estes valores aumentaram $(62,4 \% ; 60,3 \% ; 13,3 \%$, respetivamente).

De acordo com o mesmo estudo do INE (2012) verifica-se que no ano de 2012 o uso do computador era de $97,1 \%$; internet $96,8 \%$ e comércio eletrónico 19,6\%, valores referentes à faixa etária dos 16 aos 24 anos de idade; notando-se que para a faixa etária dos 45 aos 54 anos de idade um decréscimo dos valores anteriormente apresentados $(55,5 \%$; $52,2 \% ; 7,5 \%$, respetivamente), por último relativamente à faixa dos 65 aos 74 anos de idade os valores são bastante inferiores às situações anteriormente apresentadas, pelo que o uso do computador é de $17 \%$; o da Internet $16,4 \%$ e o comércio eletrónico de $2,7 \%$.

Os dados apresentados constatam que as TIC têm cada vez mais importância na atual sociedade de informação, no entanto quando se analisa o uso das TIC por faixa etária a população idosa ainda é aquela que apresenta os valores mais baixos (INE, 2012).

Perante este problema, afigurou-se relevante a exploração desta temática, tendo em conta as caraterísticas associadas ao envelhecimento, bem como as recomendações para reduzir as possíveis limitações que surgem com a idade.

O presente artigo retrata a conceção, planeamento, realização e a avaliação de tutoriais audiovisuais, de apoio ao idoso, para a utilização da comunidade miOne ${ }^{1}$ desenvolvida com e para o idoso no âmbito do projeto SEDUCE ${ }^{2}$.

\section{Enquadramento teórico}

\section{1. $O$ cidadão idoso}

\footnotetext{
2 Site informativo do projeto SEDUCE disponível no URL www.seduce.pt em 30/10/2014.
} 
De acordo com a definição das Nações Unidas (2012) com 60 ou mais anos de idade já se é considerado idoso, no entanto varia de país para país conforme a idade da reforma. Sabe-se que a idade cronológica é diferente de indivíduo para indivíduo, devido a três fatores importantes: i) o processo de envelhecimento biológico, que advém da fragilidade cada vez maior e da elevada probabilidade de morrer; ii) o envelhecimento social, pelo que o idoso deixa de ter um papel ativo na sociedade; iii) o envelhecimento psicológico, que se carateriza pela perda da capacidade de tomada de decisões e adaptação aos dois processos anteriormente referidos (Paúl, 2005). A idade biológica é difícil de definir, pois varia de indivíduo para indivíduo e tem que ver com o estado físico e mental (Rosa, 2012). A nível físico existem caraterísticas visíveis como as rugas, manchas na pele, cor do cabelo, postura, entre outras (Aiken, 1995; Ferreira, 2013 Fonseca, 2005; Pires, 2008). Quanto ao estado mental este pode estar associado a doenças do foro psíquico, ao declínio do processamento cognitivo e redução das capacidades relacionadas com a memória, atenção, entre outros (Aiken, 1995; Ferreira, 2013; Fonseca, 2005; Pires, 2008).

É importante proporcionar ao idoso a capacidade de envelhecer com qualidade e saúde, adotando um estilo de vida baseado na autonomia a nível físico, psicológico e social, possibilitando a sua integração na sociedade (Ribeiro \& Paúl, 2011). Neste contexto, o envelhecimento ativo é entendido como o acesso a oportunidades de saúde, participação e segurança, tendo como objetivo aumentar a qualidade de vida (Ribeiro \& Paúl, 2011). Neste sentido, o envelhecimento não ocorre num contexto específico (como a reforma), mas é um processo contínuo, que se carateriza pela diversidade de fatores determinantes de caráter pessoal, comportamental, económico, meio físico, social e serviços sociais e de saúde que as pessoas têm acesso (Ribeiro \& Paúl, 2011).

Com o envelhecimento são múltiplas as limitações, essas tornam-se barreiras à perceção dos conteúdos, pelo que diminuí-las utilizando os mecanismos adequados, apresenta-se como uma mais-valia. De seguida serão sucintamente elencadas quais as limitações inerentes ao envelhecimento, bem como as recomendações a ter em conta na produção de conteúdos audiovisuais adaptados aos idosos.

\subsubsection{Memória}

A memória é uma das funções mais importantes do cérebro humano: sem ela o ser humano encontra-se limitado na realização de todas as suas tarefas, desde a mais simples à mais complexa. De acordo com Zheng, Hill \& Gardner (2012), a atividade cognitiva está intrinsecamente ligada à memória. A atividade cognitiva envolve: a perceção dos impulsos sensoriais; a capacidade de aprender e manipular a informação; reconhecer objetos familiares; lembrar experiências passadas; resolução de problemas; pensamento abstrato; razão; julgamento e tomada de decisão (Zheng et al, 2012).

Afigura-se importante apresentar a arquitetura cognitiva humana, que é formada por três tipos diferentes de memória: memória sensorial, memória de trabalho e memória a longo-prazo. Apresentam-se as seguintes definições, de acordo com Zheng et al, (2012) e Fisk, Rogers, Charness, Czaja \& Sharit (2009), relativamente a cada uma das memórias:

- Memória Sensorial - esta conserva a informação temporária, que é conduzida pelo sistema nervoso central aos sentidos e que dura um curto período de tempo; 
- Memória de Trabalho - permite o processamento da informação, no entanto esta possui uma capacidade limitada, pelo que se não se fizer por mantê-la esta é rapidamente esquecida. Neste contexto o declínio desta memória origina dificuldades na produção de discurso complexo e capacidade de entendimento da linguagem, perante a existência de interferências;

- Memória a longo-prazo - capaz de armazenar uma grande quantidade de informação, durante um longo período de tempo.

Com o processo de envelhecimento existem certas dificuldades associadas à memória e que devem ser tidas em conta no desenvolvimento das TIC:

- Diminuição na rapidez do processamento e encriptação da informação, pelo que na realização de tutoriais audiovisuais a informação apresentada deve ser simplificada;

- O tempo de resposta a determinada tarefa é maior, verificando-se a necessidade de mais tempo para assimilar uma informação. Neste contexto é importante na conceção dos tutoriais audiovisuais apresentar a informação pausadamente e distanciar o tempo de apresentação de novas informações;

- Quando as tarefas são mais complexas, a capacidade de armazenar diminui. Atendendo a este facto não se deve apresentar informação complexa e redundante nos tutoriais audiovisuais;

- Maior dificuldade em relembrar acontecimentos recentes.

De acordo com as limitações inerentes à Memória, é fulcral proporcionar

\footnotetext{
${ }^{3}$ Definição retirada do dicionário Priberam [em linha], http://goo.gl/mPSiah [consultado em 16-102014]
}

ao idoso "esquemas", que possibilitam a automatização de uma tarefa através de guias passo-a-passo, que lhe permitam mecanizar as atividades a realizar para concretizar determinado objetivo (Zheng et al, 2012).

\subsubsection{Atenção}

A atenção apresenta extrema relevância quando se aborda o idoso e as dificuldades inerentes ao processo de envelhecimento. Define-se atenção como a capacidade que o indivíduo tem em estar focado numa atividade/tarefa (Fisk et al, 2009). A capacidade de reorientar a atenção, ou seja, focar num espaço e de seguida noutro é mais lenta nos idosos. É importante definir no quê que se pretende que o idoso se concentre, para que se tornem mais evidentes os elementos importantes e sejam ignorados os estímulos. Com o envelhecimento cognitivo o idoso tem dificuldade em destrinçar o que é informação relevante de informação desnecessária (Zheng et al, 2012). De acordo com esta informação, na conceção dos tutoriais audiovisuais para a população idosa, deve-se considerar reduzir a informação ao estritamente necessário e apresentar o mínimo de tarefas a realizar (Fisk et al, 2009).

\subsubsection{Visão}

A visão é o simples ato ou efeito de ver ${ }^{3}$, no entanto conforme a idade avança a acuidade visual diminui. Neste contexto é fulcral definir o termo cognição, que ocorre quando $\mathrm{o}$ cérebro recebe informação proveniente dos sentidos e modifica, reduz, guarda, recupera e utiliza essa informação (Fisk et al, 2009).

No entanto, a visão deteriora-se com a idade, constatando-se que o idoso normalmente tem dificuldade em permanecer em ambientes pouco iluminados, devido ao olho receber menos quantidade de luz, mas 
apesar deste facto a presença em ambientes demasiadamente iluminados também não se apresenta como uma boa solução (Nini, 2006). É importante referir que o idoso tem uma dificuldade três vezes superior aos jovens de se adaptar de locais bem iluminados para sítios mais escuros (Fisk et al, 2009). Outro problema tem que ver com perda da acuidade visual que pode originar visão turva e a capacidade de foco é também uma caraterística inerente ao envelhecimento do olho e que ocorre entre os 40 e os 50 anos de idade (Nini, 2006).

Considerando as dificuldades visuais, associadas ao envelhecimento, elencam-se sucintamente as estratégias a adotar na realização de tutoriais audiovisuais: a fonte deve ser legível, através do uso de fontes sem serifa e tamanho mínimo 12; devem-se evitar o uso de certas cores para a letra (por exemplo: azul); deverá haver distinção entre os cabeçalhos e o restante texto; atingir contraste de 50:1 (por exemplo: fundo preto e texto branco ou vice-versa) (Fisk et al, 2009; Zaphiris, Ghiawadwala \& Mughal, 2005). Outras recomendações são referidas por Czaja \& Sharit (2012), como: não sobrecarregar o canal visual (aliar narração ao vídeo) e evitar informação redundante e que não seja relacionada com o tema.

\subsubsection{Audição}

Aos 65 anos ou mais de idade metade da população masculina e cerca de $30 \%$ da feminina apresenta problemas auditivos, esses problemas estão inerentemente ligados à perda da capacidade de ouvir sons com mais de 4 mil vibrações por segundo. No entanto, os tons baixos não são normalmente afetados com o envelhecer (Fisk et al, 2009). A capacidade do idoso de ouvir diversificados sons é afetada. Outro problema associado à audição relaciona-se com o entendimento do discurso, porque vogais ou consoantes que necessitem de ser proferidas numa maior frequência poderão ser inaudíveis para os idosos (Fisk et al, 2009). Atendendo a esta situação mulheres e crianças, que possuem normalmente vozes mais agudas, serão mais difíceis de compreender pelos idosos.

Os tutoriais concebidos nesta investigação contêm narração e música de fundo, pelo que é relevante perceber quais são as modificações decorrentes do processo de envelhecimento e quais as recomendações que ajudam a ultrapassar essas dificuldades.

De acordo com Fisk et al (2009), os mecanismos seguintes podem ser adotados para tentar colmatar as limitações relacionadas com a audição: permitir o ajuste do som; evitar frequências abaixo dos 4000 hertz (hz); reduzir o eco e som de fundo; evitar música de fundo durante a narração e falar pausadamente, pelo que o nível do discurso deverá ser de 140 palavras por minuto. Ainda relacionado com a audição Czaja \& Sharit (2012) referem que: deve ser aliada à narração o vídeo; o canal auditivo não deve estar sobrecarregado; deve-se usar a narração e apenas adicionar palavras-chave e sincronizar a informação visual correspondente com a narração; utilizar um narrador, com estilo personalizado, que transmita calma e evitar uma conversação formal, optando antes por recorrer a uma voz amiga e a uma linguagem informal.

\subsection{Usabilidade e Acessibilidade}

De acordo com a norma ISO 9240-114, a usabilidade é definida da seguinte forma: "ponto ao qual um produto pode ser usado por utilizadores específicos para atingir

${ }^{4}$ cf. UPA - Usability Professionals Association http://goo.gl/eETsgP, acesso a 17/10/2014 
objetivos específicos com eficácia, eficiência e satisfação num determinado contexto de uso".

Por eficácia entende-se como a precisão e completude com que os utilizadores atingem os objetivos especificados. Relativamente à eficiência esta diz respeito aos recursos gastos em relação à exatidão e integridade com que os utilizadores atingem os objetivos. Por último a satisfação engloba o conforto e a aceitação do produto pelos utilizadores.

A usabilidade foca-se em permitir ao utilizador aprender a utilizar facilmente e rapidamente o design de um determinado produto, bem como na capacidade de lembrar o utilizador a manusear determinado design, após um período de tempo sem o fazer (Nielsen, 2012). Além destes fatores a usabilidade pretende proporcionar aos seus utilizadores qualidade na experiência do uso de determinado design (Nielsen, 2012).

Neste contexto, os tutoriais audiovisuais devem ser concebidos, tendo em conta as caraterísticas do idoso. É importante considerar alguns aspetos na conceção dos tutoriais, que possibilitam a que o produto final seja funcional. Esses aspetos são referidos por Nielsen (1993): texto simples, sem vocabulário técnico e que não contenha informação redundante; o utilizador não deverá ter que decorar textos e consistência, isto é, a mesma palavra não deverá ter significados diferentes por aparecer em contextos distintos.

A acessibilidade afigura-se um termo importante de definir, caraterizando-se por ser a facilidade que o indivíduo tem de aceder ao produto (Henry, 2007). Neste contexto, a acessibilidade deve ser independente das capacidades físicas, sensoriais e cognitivas de cada um, bem como do meio em que o indivíduo está inserido e a da sua literacia digital (Ferreira, 2008; Henry 2007).
Os termos usabilidade e acessibilidade complementam-se, o primeiro desenha o produto em função do públicoalvo e o segundo define que o produto deve ser fácil de usar por todos, independentemente das suas capacidades e limitações (Ferreira, 2008).

\section{Investigação Empírica}

$\mathrm{O}$ estudo centrou-se em conceber, planear, realizar e avaliar quatro tutoriais construídos para a comunidade miOne, que auxiliam o idoso a registar-se na comunidade, a fazer uma visita as áreas disponíveis na comunidade, a utilizar o correio eletrónico e a conversar através do sistema de conversas (mensagens instantâneas - bate-papo).

\subsection{Metodologia}

Para executar esta investigação foram utilizadas três metodologias diferentes aplicadas em três fases distintas da investigação: exploratória, investigação-ação e avaliação. A Tabela 1 apresenta a calendarização das fases e respetivas etapas de investigação para conceber, planear, realizar e avaliar quatro tutoriais audiovisuais para a comunidade miOne.

$\mathrm{Na}$ primeira fase, metodologia exploratória, foi realizada uma análise documental, que tinha como objetivo fazer a revisão da literatura e investigar o trabalho científico já realizado na área (Coutinho, 2011) para auxiliar na conceção da primeira versão dos tutoriais. Esta fase terminou com a realização da primeira versão dos tutoriais e guiões de voz-off, presentes na primeira sessão de focus group da fase seguinte.

$\mathrm{Na}$ segunda fase, a metodologia investigação-ação que corresponde a um processo cíclico (Coutinho, 2011), em que se misturam e interligam, permanentemente, a 
teoria e prática. Esta metodologia caraterizase efetuar mudanças e intervenções até se conseguir resolver o problema. Nesta fase da investigação realizaram-se quatro sessões de focus group, onde os guiões de voz-off foram reestruturados até à versão final, quando se consideraram adequados para o público alvo.

Tabela 1 - Calendarização das fases e etapas de investigação para conceber, planear, realizar e avaliar quatro tutoriais audiovisuais para a comunidade miOne

\begin{tabular}{|c|c|c|c|c|}
\hline Fases & Etapas & Data & Atividade & $\begin{array}{l}\text { Técnica e instrumentos de } \\
\text { recolha de dados }\end{array}$ \\
\hline $\begin{array}{l}\text { Primeira Fase } \\
\text { (Metodologia } \\
\text { Exploratória) }\end{array}$ & $\begin{array}{l}\text { Primeira } \\
\text { Etapa }\end{array}$ & $\begin{array}{l}20 / 09 / 2013 \\
\text { a } \\
15 / 03 / 2014\end{array}$ & $\begin{array}{l}\text { Recolha e Revisão do } \\
\text { Material Bibliográfico e } 1^{\text {a }} \\
\text { versão dos tutoriais e guiões } \\
\text { de voz-off }\end{array}$ & $\begin{array}{l}\text { Análise Documental/ Fichas } \\
\text { de Leitura }\end{array}$ \\
\hline \multirow{4}{*}{$\begin{array}{l}\text { Segunda Fase } \\
\text { (Metodologia } \\
\text { Investigação- } \\
\text { ação) }\end{array}$} & $\begin{array}{l}\text { Primeira } \\
\text { Etapa }\end{array}$ & $8 / 05 / 2014$ & $\begin{array}{l}1^{\text {a }} \text { versão Guião de Voz-Off e } \\
1^{\text {a }} \text { versão dos tutoriais } \\
\text { Originou a } 2^{\mathrm{a}} \text { versão Guião de } \\
\text { Voz-Off }\end{array}$ & $\begin{array}{l}\text { Focus Group/ Observação } \\
\text { Participante (Notas de } \\
\text { Campo) }\end{array}$ \\
\hline & $\begin{array}{l}\text { Segunda } \\
\text { Etapa }\end{array}$ & $22 / 05 / 2014$ & $\begin{array}{l}2^{\mathrm{a}} \text { versão Guião Voz-Off } \\
\text { Originou a } 3^{\mathrm{a}} \text { versão Guião de } \\
\text { Voz-Off }\end{array}$ & $\begin{array}{l}\text { Focus Group/ Observação } \\
\text { Participante (Notas de Campo) }\end{array}$ \\
\hline & $\begin{array}{l}\text { Terceira } \\
\text { Etapa }\end{array}$ & 29/05/2014 & $\begin{array}{l}3^{\mathrm{a}} \text { versão Guião Voz-Off } \\
\text { Originou a } 4^{\mathrm{a}} \text { versão Guião de } \\
\text { Voz-Off (os guiões de voz-off } \\
\text { relativos ao registo e visita à } \\
\text { comunidade ficaram } \\
\text { finalizados nesta fase) }\end{array}$ & $\begin{array}{l}\text { Focus Group/ Observação } \\
\text { Participante (Notas de Campo) }\end{array}$ \\
\hline & $\begin{array}{l}\text { Quarta } \\
\text { Etapa }\end{array}$ & $5 / 06 / 2014$ & $\begin{array}{l}4^{\mathrm{a}} \text { versão Guião Voz-Off } \\
\text { Originou a } 5^{\mathrm{a}} \text { versão Guião de } \\
\text { Voz-Off relativo ao Correio } \\
\text { Eletrónico e Conversar } \\
\text { Realização e validação dos } \\
\text { tutoriais }\end{array}$ & $\begin{array}{l}\text { Focus Group/ Observação } \\
\text { Participante (Notas de Campo) }\end{array}$ \\
\hline \multirow{2}{*}{$\begin{array}{l}\text { Terceira Fase } \\
\text { (Metodologia } \\
\text { Avaliação) }\end{array}$} & $\begin{array}{l}\text { Primeira } \\
\text { Etapa }\end{array}$ & $10 / 10 / 2014$ & Entrevista Exploratória & $\begin{array}{l}\text { Entrevista semiestruturada; } \\
\text { Inquérito por questionário } \\
\text { para caraterizar a amostra; } \\
\text { Inquérito por questionário } \\
\text { para ordenar as atividades; } \\
\text { Gravação áudio das } \\
\text { entrevistas e posterior } \\
\text { transcrição para análise do } \\
\text { conteúdo; }\end{array}$ \\
\hline & $\begin{array}{l}\text { Segunda } \\
\text { Etapa }\end{array}$ & $\begin{array}{l}14 / 10 / 2014 \\
a \\
17 / 10 / 2014\end{array}$ & Avaliação dos Tutoriais & $\begin{array}{l}\text { Entrevista semiestruturada; } \\
\text { Inquérito por questionário } \\
\text { para caraterizar a amostra; } \\
\text { Inquérito por questionário } \\
\text { para ordenar as atividades; } \\
\text { Gravação áudio das } \\
\text { entrevistas e posterior } \\
\text { transcrição para análise do } \\
\text { conteúdo; }\end{array}$ \\
\hline
\end{tabular}

A terceira fase, metodologia de avaliação pretende aumentar os conhecimentos existentes; compara os resultados obtidos com os objetivos previamente definidos e 
propõe-se justificar as decisões tomadas sobre o que se avalia (Coutinho, 2011). Atendendo a este contexto, os tutoriais realizados foram submetidos a uma avaliação por parte de idosos de uma Universidade Sénior, nas categorias: vídeo, voz-off e música de fundo.

\subsection{Técnicas e instrumentos de recolha de dados}

\subsubsection{Focus Group e Notas de campo}

Segundo Gray (2009) as notas de campo são escritas quando se realiza uma entrevista ou observação no campo; estas podem incluir comentários e interpretações do próprio investigador. De acordo com o mesmo autor a técnica de focus groups normalmente refere-se a uma discussão realizada com um conjunto de indivíduos em grupo em torno de um mesmo assunto. $\mathrm{Na}$ segunda fase desta investigação as notas de campo serviram para recolher informação durante as sessões de focus groups para desenvolver os guiões vozoff dos quatro tutoriais.

\subsubsection{Inquérito por questionário para caraterização dos participantes}

Segundo Fisk et al (2009) é fulcral saber sobre as caraterísticas da amostra, afigurando-se necessário a utilização de um inquérito por questionário, que permita efetuar a sua caraterização. Este questionário deve incluir questões como idade, género, educação, entre outros atributos considerados relevantes para a investigação (Fisk et al, 2009). Neste contexto, utilizou-se um inquérito por questionário para caraterizar a amostra estruturado em três áreas:

1) Dados sociodemográficos, que recolheu informações sobre idade, género, naturalidade, estado civil, profissão e habilitações literárias;
2) Comunicação e Informação, que recolheu informações sobre o meio de comunicação mais frequente, leitura de jornais e revistas, visualização de televisão e tempo dedicado a esta atividade e tipo de programas visualizados;

3) Contexto de utilização do computador, que apresentava um conjunto de questões que pretendiam aferir sobre a utilização do computador, local de utilização, frequência e atividades realizadas.

Este inquérito por questionário foi utilizado para caraterizar os participantes idosos que estiveram envolvidos nesta investigação.

\subsubsection{Entrevista Semiestruturada}

Um outro instrumento de recolha de dados utilizado na terceira fase desta investigação foi a realização de um guião de entrevista semiestruturado que permitiu avaliar os tutoriais junto do público-alvo.

Para a consolidação do guião de entrevista semiestruturado realizou-se uma entrevista exploratória com dois seniores que já tinham participado em atividades do projeto SEDUCE e utilizado a comunidade miOne. A realização desta entrevista permitiu aferir quais seriam as categorias e subcategorias que se pretendiam analisar, bem como estruturar adequadamente as perguntas a efetuar. Também possibilitou perceber o tipo de respostas para cada uma das questões colocadas e permitiu notar o tempo despendido na entrevista. Este guião de entrevista semiestruturado foi posteriormente utilizado nas entrevistas com os idosos da Universidade Sénior Florbela Espanca (USFE). A Tabela 2 apresenta a organização das questões formuladas no guião de entrevista semiestruturada, bem como as categorias e subcategorias definidas para a análise do conteúdo das respostas. 
Tabela 2 - Organização das perguntas do guião de entrevista semiestruturada, com as categorias e subcategorias de análise

\begin{tabular}{|c|c|c|}
\hline Categoria & Subcategoria & Pergunta \\
\hline \multirow{3}{*}{ Vídeo } & Nitidez & $\begin{array}{l}\text { Acha que as imagens eram nítidas? Acha que se percebe a nível visual } \\
\text { o que se está a mostrar? }\end{array}$ \\
\hline & $\begin{array}{l}\text { Ritmo da } \\
\text { informação visual }\end{array}$ & $\begin{array}{l}\text { Relativamente ao ritmo de apresentação da informação, consegue } \\
\text { compreender todos os passos que vão sendo mostrados? }\end{array}$ \\
\hline & $\begin{array}{l}\text { Equilíbrio da } \\
\text { narração e vídeo }\end{array}$ & $\begin{array}{l}\text { Relativamente ao equilíbrio entre a narração e a informação mostrada } \\
\text { no vídeo. Ou seja, acha que a narração está articulada com que é } \\
\text { apresentado no vídeo? }\end{array}$ \\
\hline \multirow{4}{*}{ Voz-off } & $\begin{array}{l}\text { Perceção voz } \\
\text { masculina }\end{array}$ & Percebe a voz masculina? \\
\hline & $\begin{array}{l}\text { Perceção voz } \\
\text { feminina }\end{array}$ & Percebe a voz feminina? \\
\hline & $\begin{array}{l}\text { Alternância de } \\
\text { vozes }\end{array}$ & $\begin{array}{l}\text { Conseguiu perceber o porquê da alteração da masculina para a } \\
\text { feminina? }\end{array}$ \\
\hline & Velocidade da fala & Como considera a velocidade da fala? \\
\hline \multirow{2}{*}{$\begin{array}{l}\text { Música de } \\
\text { fundo }\end{array}$} & $\begin{array}{l}\text { Perceção da Música } \\
\text { de Fundo }\end{array}$ & Notou que havia uma música de fundo? \\
\hline & Compreensão Vozes & Acha que a música de fundo perturba a compreensão das vozes? \\
\hline
\end{tabular}

\subsubsection{Inquérito por questionário para ordenar as atividades realizadas}

$\mathrm{O}$ inquérito por questionário para a ordenação das atividades foi o instrumento utilizado para a recolha de dados sobre o conjunto de tarefas explicadas no tutorial para atingir os objetivos de cada um dos tutoriais. Neste contexto, fornecia-se um guião com uma a lista de tarefas do respetivo tutorial que devia ser ordenada corretamente. A correta ordenação significaria a perceção de cada um dos tutoriais. Os participantes deviam ordenar de 1 a 5 os passos a realizar para concretizar o objetivo. Neste sentido, o número 1 seria o primeiro passo a realizar e o número 5 o último passo a efetuar para atingir o objetivo. Tomando como exemplo o Tutorial 1 "Registo na comunidade miOne", pretendia-se que os participantes ordenassem de 1 a 5 os passos para se registar na comunidade miOne. A realização desta tarefa pretendia apurar se os participantes tinham percecionado o conteúdo do tutorial.

\subsection{Caraterização dos Participantes da investigação}

Os participantes desta investigação dividem-se em dois grupos distintos, os especialistas que participaram nas sessões de focus groups e os idosos que participaram na avaliação dos tutoriais.

\subsubsection{Caraterização dos Participantes do focus group}

Estiveram presentes nas sessões de focus group seis investigadores da área. Desse grupo, cinco investigadores eram doutorados e um deles era mestre, no entanto todos estavam ligados pela investigação e participação ao projeto SEDUCE, bem como a investigação em áreas interligadas com as TIC e com a interação humano-computador. Estes participantes pela sua especialização permitiram introduzir importantes reestruturações nos guiões de voz-off através 
das discussões nas sessões de focus group de forma a adequá-los para o público idoso.

\subsubsection{Caraterização dos Participantes da entrevista exploratória}

Quanto aos participantes da entrevista exploratória, relativamente aos dados sociodemográficos do inquérito por questionário, podem-se aferir os seguintes dados: um era do sexo feminino e outro do masculino, ambos eram casados, portugueses e quanto às habilitações um possuía o bacharelato e outro o $12^{\circ}$ ano de escolaridade.

Em relação à segunda parte do inquérito por questionário "Comunicação e Informação" ambos referiram que utilizavam o telefone para comunicar, no entanto um dos participantes também mencionou a carta, telemóvel e computador. Ambos os entrevistados afirmaram que liam revistas, pelo que um lia revistas de várias áreas e outro revistas relacionadas com a música. Apenas um dos inquiridos lia jornais, frisando alguns como Jornal de Notícias, Diário de Aveiro, SOL, entre outros. Ambos os entrevistados viam diariamente televisão, referindo que visualizavam programas relacionados com cinema e concertos.

$\mathrm{Na}$ terceira e última parte do inquérito por questionário, relativa ao contexto de utilização do computador, os dados obtidos foram os seguintes: os dois inquiridos já tinham usado o computador em casa ou em instituições, fazendo-o sozinhos ou acompanhados pelos cônjuges; ambos os entrevistados mencionaram que o utilizavam diariamente para atividades como enviar e receber e-mails, escrever, comunicar via computador e pesquisar e consultar informação.

Pelos dados apresentados denota-se que estes participantes possuíam alguns conhecimentos no uso das TIC.

\subsubsection{Caraterização dos Participantes da USFE}

Este grupo de participantes da USFE é constituído por 9 idosos. Relativamente aos dados sociodemográficos pôde-se aferir o seguinte: $7 / 9$ dos entrevistados eram do sexo feminino; as idades variavam entre os 64 e 75 anos de idade $(\mathrm{M}=68 ; \mathrm{SD}=3,5) ; \mathrm{a}$ licenciatura é a habilitação literária que se destaca (5/9), pelo que havia um participante com o ensino primário, outro com o $12^{\circ}$ ano de escolaridade, um dos participantes possuía um bacharelato e outro um mestrado; os 9 participantes eram reformados; 8/9 dos participantes eram naturais do distrito do Porto e um dos participantes era de Caracas (Venezuela); quanto ao estado civil 5/9 dos entrevistados eram casados, 2 viúvos, 2 divorciados e 1 solteiro.

Em relação à segunda parte do inquérito questionário "Comunicação e Informação" obtiveram-se os seguintes dados: 7/9 dos inquiridos referem que o meio de comunicação mais utilizado é o telemóvel; todos os inquiridos leem revistas e jornais; todos os inquiridos dedicam algum tempo à televisão, principalmente a visualizar telejornais e debates.

$\mathrm{Na}$ terceira e última parte do inquérito questionário, relativa ao contexto de utilização do computador, constataram-se as seguintes informações: todos os idosos já o utilizaram o computador, fazendo um uso diário deste sozinhos ou acompanhados; os inquiridos afirmaram que utilizam $O$ computador em diversas atividades, elencando-se de seguida as que mereceram mais destaque: enviar e receber e-mails, aceder a serviços, ver imagens de lugares e visualizar vídeos e pesquisar informação sobre saúde.

Pelos dados obtidos constata-se que os participantes na avaliação da USFE possuem alguns conhecimentos a nível do uso das TIC 
podendo facultar inputs importantes na avaliação dos tutoriais.

\subsection{Realização dos tutoriais}

Para a realização dos tutoriais, foi necessário planear os guiões de voz-off. Neste contexto realizaram-se quatro sessões de focus group que permitiram a reestruturação dos guiões de voz-off até à sua versão final.

Nessas sessões estiveram presentes os investigadores anteriormente referidos e caraterizados como especialistas.

As Tabelas 3, 4, 5 e 6 apresentam sumariamente as mudanças realizadas em cada uma das sessões para cada um dos guiões de voz-off, tutorial 1, tutorial 2, tutorial 3 , tutorial 4 , respetivamente.

Nas frases das tabelas as palavras riscadas, significam que as palavras foram eliminadas quando apresentadas na respetiva sessão de focus group, e as palavras a negrito foram acrescentadas nas frases na sessão de focus group.

A Tabela 3 apresenta o sumário das sessões de focus group na organização do guião voz-off do tutorial 1 que corresponde ao "Registo na Comunidade miOne".

A Tabela 4 apresenta o sumário das sessões de focus group para organização do guião voz-off do tutorial 2 correspondente à "Visita à Comunidade miOne". Os tutoriais 1 e 2 ficaram finalizados na terceira sessão de focus group.

Tabela 3 - Sumário das sessões de focus group para organização do guião voz-off do tutorial 1 correspondente ao "Registo na Comunidade miOne"

\begin{tabular}{|c|c|c|}
\hline $\begin{array}{l}1^{\text {a }} \text { Sessão de Focus } \\
\text { Group }\end{array}$ & $2^{\mathrm{a}}$ Sessão de Focus Group & $3^{\text {a }}$ Sessão de Focus Group \\
\hline $\begin{array}{l}\text { - O tutorial } 2 \\
\text { também fazia parte } \\
\text { desta versão do } \\
\text { guião de voz-off } \\
\text { relativo ao tutorial 1; } \\
\text { - Definiu-se que } \\
\text { haveria um tutorial } \\
\text { dedicado ao registo, } \\
\text { que seria apresentado } \\
\text { na } 2^{\mathrm{a}} \text { sessão de focus } \\
\text { group. }\end{array}$ & $\begin{array}{l}\text { - Sugestões de alteração das } \\
\text { seguintes frases: } \\
\text { 1) Escreva o seu nome na caixa } \\
\text { amarela o máximo é de } 40 \\
\text { earacteres. } \\
\text { 2) Assinale-Indique se é do sexø } \\
\text { género feminine masculino ou } \\
\text { masculine feminino. } \\
\text { 3) Eonforme leia o texto clique } \\
\text { em Mostrar mais texto para ler } \\
\text { todos os termes. Se pretender ler } \\
\text { algo que já desapareceu do ecrã, } \\
\text { elique em Mostrar Menes Texto. } \\
\text { Clique nos botões "Mostrar mais } \\
\text { texto" e "Mostrar menos texto" } \\
\text { para ler as condições ao seu ritmo. } \\
\text { - Inserção de novas frases: } \\
\text { 1) Com o seu registo finalizado } \\
\text { sempre que quiser entrar na } \\
\text { comunidade miOne, escreva o seu } \\
\text { endereço de correio eletrónico e a } \\
\text { sua senha. }\end{array}$ & $\begin{array}{l}\text { - Alteração da ordem de uma frase; } \\
\text { - A seguinte frase dividiu-se em } \\
\text { duas: } \\
\text { 1) Escreva a sua data de nascimento. } \\
\text { Devendo preencher primeiro o dia, } \\
\text { depois o mês e por último o ano. } \\
\text { 1.1) Escreva a sua data de } \\
\text { nascimento. } \\
\text { 1.2) Deve preencher primeiro o dia, } \\
\text { depois o mês e por último o ano. } \\
\text { - Inserção de novas frases: } \\
\text { 1) Este registo é só seu, para isso } \\
\text { precisa de uma senha para aceder à } \\
\text { comunidade de forma segura e } \\
\text { privada. } \\
\text { 2) Repita a senha. } \\
\text { - Definição das frases a serem } \\
\text { narradas pela voz feminina: } \\
\text { 1) Pode optar no início por esconder } \\
\text { a senha, clique no quadrado onde diz } \\
\text { Esconder Senha. } \\
\text { 2) Pode escrever um endereço de } \\
\text { correio eletrónico alternativo para } \\
\text { recuperar a senha, caso se esqueca. }\end{array}$ \\
\hline
\end{tabular}


Tabela 4 - Sumário das sessões de focus group para organização do guião voz-off do tutorial 2 que mostra a "Visita à Comunidade miOne"

\begin{tabular}{|c|c|c|}
\hline $\begin{array}{l}1^{\text {a }} \text { Sessão de } \\
\text { Focus Group }\end{array}$ & $2^{\text {a }}$ Sessão de Focus Group & $3^{\text {a }}$ Sessão de Focus Group \\
\hline $\begin{array}{l}\text { - O tutorial } 1 \\
\text { também fazia parte } \\
\text { desta versão do } \\
\text { guião de voz-off } \\
\text { do tutorial 2; } \\
\text { - Definiu-se que } \\
\text { haveria um tutorial } \\
\text { dedicado à visita à } \\
\text { comunidade } \\
\text { apresentado na } 2^{\text {a }} \\
\text { sessão de focus } \\
\text { group. }\end{array}$ & $\begin{array}{l}\text { - Sugestões de alteração de frases: } \\
\text { 1) Depois de entrar na comunidade } \\
\text { Eesta é a sua área pessoal. Na } \\
\text { comunidade miOne pode comunicar com } \\
\text { os seus familiares e amigos, consultar } \\
\text { informação sobre saúde, noticias e jogar. } \\
\text { Atualizar os seus interesses no perfil, } \\
\text { veja ver as últimas novidades na } \\
\text { comunidade e explorar o que pode fazer } \\
\text { nas opções de navegação. } \\
\text { 2) Também na sua área pessoal pode } \\
\text { saber o que os seus amigos estão a fazer } \\
\text { ende diz Descubra o que os seus amigos } \\
\text { estão a fazer. } \\
\text { - Definição de termos transversais a } \\
\text { todos os tutoriais: } \\
\text { 1) Clique na ligação para a área } \\
\text { 2) Clique no botão } \\
\text { 3) Clique no separador } \\
\text { 4) miOne a vida em comunidade para } \\
\text { mim, para si, para todos. } \\
\text { - Inserção de novas frases: } \\
\text { 1) Vamos fazer uma visita pelas áreas da } \\
\text { comunidade miOne. }\end{array}$ & $\begin{array}{l}\text { - Sugestões de alteração de } \\
\text { frases: } \\
\text { 1) Depois de entrar na } \\
\text { comunidade esta é a sua } \\
\text { área pessoal. Na } \\
\text { comunidade miOne pode } \\
\text { comunicar com os seus } \\
\text { familiares e amigos, } \\
\text { consultar informação sobre } \\
\text { saúde, noticias e jogar jogos } \\
\text { e partilhar experiências. } \\
\text { Pode também Aatualizar } \\
\text { os seus interesses no perfil, } \\
\text { ver as últimas novidades na } \\
\text { comunidade e explorar o } \\
\text { que pode fazer nas opções } \\
\text { de navegação. } \\
\text { 2) Nesta área pode realizar } \\
\text { tárias atividades ler e } \\
\text { partilhar experiências. } \\
\text { Descubra cada uma delas } \\
\text { clicando nos botões. }\end{array}$ \\
\hline
\end{tabular}

A Tabela 5 apresenta o sumário das sessões de focus group para organização do guião voz-off do tutorial 3 que explica o modo "Como usar o correio eletrónico da comunidade miOne". O tutorial 4 também fazia parte da primeira versão do guião de voz-off do tutorial 3, mas na primeira sessão de focus group do tutorial 3 definiu-se que haveria um tutorial unicamente dedicado a explicar o uso do correio eletrónico apresentado na segunda sessão de focus group.

Tabela 5 - Sumário das sessões de focus group para organização do guião voz-off do tutorial 3 que explica o modo "Como usar o correio eletrónico da comunidade miOne"

\begin{tabular}{|c|c|c|}
\hline $2^{\mathrm{a}}$ Sessão de Focus Group & $3^{\text {a }}$ Sessão de Focus Group & $\begin{array}{l}4^{a} \text { Sessão de } \\
\text { Focus Group }\end{array}$ \\
\hline $\begin{array}{l}\text { - Sugestões de alteração de } \\
\text { frases: } \\
\text { 1) Para aceder à área } \\
\text { Commnicar, clique em } \\
\text { Commnicar. Clique na ligação } \\
\text { para a área Comunicar. } \\
\text { 2) Aparece-lhe uma mensagem } \\
\text { que lhe pede que aAguarde um } \\
\text { pouco. }\end{array}$ & $\begin{array}{l}\text { - Sugestões de alteração de frases: } \\
\text { 1) Pode ambém adicionar mais-contactos } \\
\text { clicando na caixa de diálogo situada em baixo. } \\
\text { 2) Se pretender enviar um pedido de amizade } \\
\text { para a pessoa à qual pertence o endereço de } \\
\text { eorreio eletrónico que esereveu, clique Sim } \\
\text { Enviar, se não clique em Agora Não. Para } \\
\text { iniciar a construção da sua lista de amigos } \\
\text { envie um pedido de amizade para a pessoa à }\end{array}$ & $\begin{array}{l}\text { - Eliminação de } \\
\text { uma frase: } \\
\text { 1) Em qualquer } \\
\text { altura pode } \\
\text { reenviar as suas } \\
\text { mensagens. } \\
\text { - Alteração da } \\
\text { ordem de uma } \\
\text { frase; }\end{array}$ \\
\hline
\end{tabular}




\begin{tabular}{|l|l|l|}
\hline 3) Clique em Adicionar Ppara & qual pertence o endereço de correio eletrónico \\
adicionar o ficheiro à & que escreveu. Clique no botão Sim Enviar. & - Definição de \\
mensagem elique em & - Eliminação de frases: & mais uma frase a \\
Adicionar. & 1) Clique no botão Adicionar amigos. Escolha & ser narrada pela \\
- Inserção de novas frases: & na lista de membros da comunidade & voz feminina: \\
1) Clique na caixa amarela em & apresentada, qual o amigo que pretende & 1) Pode optar por \\
apagar todas as \\
frente ao título, para alterar o & adicionar. & 2) Clique na caixa amarela em frente ao Para, \\
título da mensagens. & para \\
2) A sua mensagem foi movida \\
para as mensagens apagadas. & - Inserção de novas frases: & Apagar Todas as \\
- Definição das frases a serem & 1) Pode também Apagar, Reenviar, Responder & Mensagens. Ou \\
narradas pela voz feminina: & a Todos ou Responder, tendo que para isso & se pretender \\
apagar uma & Se for a primeira vez que \\
acede a esta área é normal que & clicar nos respetivos botões. & 2) Pode optar por apagar todas as mensagens, \\
não tenha mensagens recebidas. & clicando no botão Apagar Todas as & abrir a mensagem \\
2) Pode adicionar um anexo, & Mensagens. Ou se pretender apagar uma & e clicar no botão \\
que pode ser uma imagem, um & mensagem, deve abrir a mensagem e clicar no & Apagar. \\
documento ou um vídeo. & botão Apagar. & \\
\hline
\end{tabular}

A Tabela 6 apresenta o sumário das sessões de focus group para organização do guião voz-off do tutorial 4 que explica o modo "Como conversar na comunidade miOne". O tutorial 4 também fazia parte da primeira versão do guião de voz-off do tutorial 3, mas na primeira sessão de focus group do tutorial 3 definiu-se que haveria um tutorial unicamente dedicado a explicar como conversar na comunidade miOne apresentado na segunda sessão de focus group.

Tabela 6 - Sumário das sessões de focus group para organização do guião voz-off do tutorial 4 que explica o modo "Como conversar na comunidade miOne"

\begin{tabular}{|c|c|c|}
\hline $2^{\mathrm{a}}$ Sessão de Focus Group & $3^{\text {a }}$ Sessão de Focus Group & $4^{\text {a }}$ Sessão de Focus Group \\
\hline $\begin{array}{l}\text { - Sugestões de alteração de } \\
\text { frases: } \\
\text { 1) Para poder conversar com } \\
\text { os seus amigos deve ter um } \\
\text { visto no quadrado onde diz } \\
\text { Estou disponível para } \\
\text { conversar. } \\
\text { 2) A tabela lista do lado } \\
\text { direito apresenta mostra } \\
\text { quem está disponível para } \\
\text { conversar. } \\
\text { - Definição da frase a ser } \\
\text { narrada pela voz feminina: } \\
\text { 1) Pode conversar em tempo } \\
\text { real com os seus amigos }\end{array}$ & $\begin{array}{l}\text { - Sugestões de alteração de frases: } \\
\text { 1) Para conversar com os seus } \\
\text { amigos deve ter um visto no } \\
\text { quadrado onde diz Estou disponível } \\
\text { para conversar. Verifique se está } \\
\text { disponível para conversar. } \\
\text { 2) Clique no botão fechar conversa, } \\
\text { se não pretender conversar mais. } \\
\text { Pode prolongar a conversa } \\
\text { enquanto ambos estiverem } \\
\text { disponíveis para conversar. Se não } \\
\text { pretender conversar mais clique no } \\
\text { botão Fechar Conversa. } \\
\text { - Inserção de uma frase: } \\
\text { 1) Neste tutorial iremos aprender a } \\
\text { utilizar as mensagens instantâneas } \\
\text { (Conversa). } \\
\text { - União de frases. }\end{array}$ & $\begin{array}{l}\text { - Inserção de uma frase a ser } \\
\text { narrada pela voz feminina: } \\
\text { 1) Note que alguns dos seus } \\
\text { amigos podem não estar } \\
\text { disponíveis para conversar. } \\
\text { - Sugestões de alteração de } \\
\text { frases: } \\
\text { 1) A lista do lado direito mostra } \\
\text { quem está disponível para } \\
\text { conversar. A lista do lado } \\
\text { direito apresenta os seus } \\
\text { amigos. Escolha um dos seus } \\
\text { amigos que esteja disponível } \\
\text { para conversar. } \\
\text { - Divisão de uma frase em } \\
\text { duas. }\end{array}$ \\
\hline
\end{tabular}


Pela leitura das Tabelas 3, 4, 5 e 6 podese constatar que os guiões de voz-off de cada um dos tutoriais foram reestruturados até se conseguir atingir uma versão adequada para o contexto da comunidade miOne. De acordo com as alterações presentes nas tabelas podese notar que na primeira sessão de focus group, definiram-se as linhas gerais dos tutoriais, bem como os requisitos que estes deveriam cumprir. Nesta primeira sessão os guiões de voz-off e os tutoriais elaborados na primeira fase, que aliavam imagens reais e capturas de ecrã foram revistos, porque estavam muito extensos. Um tutorial mostrava o registo e visita à comunidade e o outro explicava como usar o correio eletrónico e como conversar na comunidade.

Além do tamanho, a voz-off utilizada era a de um idoso e foi considerada maçadora, definindo-se o uso de duas vozes uma masculina (narra os passos principais) e outra feminina (informa os passos adicionais/opcionais). Para além disso também a utilização de termos sinónimos, frases complexas e a falta de termos familiares ao utilizador da comunidade miOne, inviabilizaram estes guiões de voz-off, considerando-se necessária a construção de novos guiões tendo em conta estas indicações, bem como as referidas por alguns autores, de seguida apresentadas.

De acordo com Czaja \& Sharit (2012), deve-se adotar um narrador com estilo personalizado, que transmita calma. Deve-se evitar uma conversação formal, optando antes por recorrer a uma voz amiga e a uma linguagem informal (Czaja \& Sharit, 2012). Segundo Nielsen (1993) deve-se ainda adotar: frases simples, sem informações redundantes; conceitos familiares ao utilizador; consistência, o utilizador não deverá ter que analisar se a mesma palavra em diferentes contextos tem significados diferentes.

Neste contexto e atendendo às recomendações anteriores, os guiões de voz- off foram reestruturados até estarem adequados à população iodosa. As segundas e terceiras sessões de focus group, bem como a quarta sessão, realizada apenas para analisar o Tutorial 3 e o Tutorial 4, centraram-se maioritariamente para todos os guiões de voz-off considerados, nas seguintes alterações: reestruturação de frases para que estas fossem mais simples e curtas; utilização de termos familiares ao utilizador da comunidade miOne; inserção de frases que clarificassem a explicação de determinado tutorial; eliminação de frases que não fossem consideradas importantes; definição das frases a serem narradas pela voz-off feminina; definição de termos transversais a todos os tutoriais e correções gramaticais.

Concluído o planeamento dos guiões de voz-off, o passo seguinte foi a gravação das vozes-off, masculina e feminina em espaços próprios para o efeito, para que de acordo com Fisk et al (2012) não exista som de fundo e eco. Depois deste momento foram realizadas as capturas de ecrã utilizando o software próprio para o efeito e de seguida, iniciaram-se os trabalhos de edição para cada um dos tutoriais. Finalizados os tutoriais, estes foram validados e disponibilizados na plataforma Youtube, podendo ser visualizados nos seguintes links:

- Tutorial 1 - Registo na comunidade miOne - http://goo.gl/5Z7lHX

- Tutorial 2 - Visita à comunidade miOne - http://goo.gl/VWq7Sn

- Tutorial 3 - Como usar o correio eletrónico na comunidade miOne http://goo.gl/SvcGwz

- Tutorial 4 - Como conversar na comunidade miOne

http://goo.gl/xmlSOO

\subsection{Avaliação dos Tutoriais}


Para a avaliação dos tutoriais, foram realizadas entrevistas com grupos de duas pessoas, com participantes da Universidade Sénior Florbela Espanca.

Estas entrevistas ocorreram nas instalações da referida universidade, tiveram a duração de uma hora e de acordo, com o consentimento dado pelos participantes foram gravadas para posterior transcrição do conteúdo das respostas. Para manter o anonimato dos participantes foi-lhes atribuída a designação de $\mathrm{P}$ (participante) e aleatoriamente numerados de 1 a 11 .
Nestas entrevistas pretendeu-se avaliar os tutoriais nas categorias vídeo, voz-off e música de fundo, anteriormente explicadas.

Após a visualização dos tutoriais os nove participantes das entrevistas realizaram uma atividade que pretendia verificar se estes tinham percecionado os tutoriais. Essa atividade consistia na ordenação dos passos para realizar determinada tarefa, tendo em conta o tutorial visualizado.

As tabelas 7, 8, 9 e 10 apresentam os resultados relativos à ordenação dos passos para cada um dos tutoriais.

Tabela 7 - Apresentação dos resultados de ordenação das tarefas realizadas pelos participantes para o Registo na Comunidade miOne

Tutorial 1 - Registo na Comunidade miOne
Tarefa: Ordenar de 1 a 5 os passos a efetuar para se registar na comunidade miOne.
\begin{tabular}{|l|l|}
\hline Respostas \\
\hline P3: & Correto. \\
\hline P4: & Errou na ordenação de um dos passos. \\
\hline P5: & Tem o último passo correto. \\
\hline P6: & Correto. \\
\hline P7: & Errou na ordenação de um dos passos. \\
\hline P8: & Correto. \\
\hline P9: & Correto. \\
\hline P10: & Correto. \\
\hline P11: & Correto. \\
\hline
\end{tabular}

A Tabela 7 apresenta os resultados da ordenação dos passos para se registar na comunidade miOne conforme explica o Tutorial 1, notando-se que 6/9 dos participantes acertaram na ordenação dos passos; 2/9 dos participantes erraram na ordenação de um dos passos e $1 / 9$ dos participantes ordenou corretamente um passo.

Tabela 8 - Apresentação dos resultados de ordenação das tarefas realizadas pelos participantes para Visita à Comunidade miOne

\section{Tutorial 2 - Visita à Comunidade miOne}

Tarefa: Ordenar de $\mathbf{1}$ a 5 as áreas mostradas no tutorial relativo à visita à comunidade miOne.

Respostas

P3: $\quad$ Correto.

P4: $\quad$ Tem o último e penúltimo corretos, o restante está trocado. 


\begin{tabular}{|l|l|}
\hline P5: & Errou na ordenação de um dos passos. \\
\hline P6: & Errou na ordenção de um dos passos. \\
\hline P7: & Errou na ordenação de um dos passos. \\
\hline P8: & Tem o último e penúltimo corretos, o restante está trocado. \\
\hline P9: & Tem correta a ordem de apenas um dos passos. \\
\hline P10: & Tem o último e penúltimo corretos, o restante está trocado. \\
\hline P11: & Errou na ordenação de um dos passos. \\
\hline
\end{tabular}

A Tabela 8 mostra os resultados relativos à ordenação dos passos para a visita à comunidade miOne como explica o Tutorial 2, constatando-se que $4 / 9$ dos participantes ordenaram corretamente o último e o penúltimo passos; 4/9 dos participantes erraram na ordenação de um dos passos e 1/9 dos participantes ordenou corretamente todos os passos.

Tabela 9 - Apresentação dos resultados de ordenação das tarefas realizadas pelos participantes para usar o Correio Eletrónico da Comunidade miOne

Tutorial 3 - Como usar o Correio Eletrónico da Comunidade miOne
Tarefa: Ordenar de 1 a 5 os passos para enviar uma mensagem na comunidade miOne.
\begin{tabular}{l|l|}
\hline Respostas \\
\hline P3: & Correto. \\
\hline P4: & Correto. \\
\hline P5: & Correto. \\
\hline P6: & Tem o último e penúltimo corretos, o restante está trocado. \\
\hline P7: & Tem o último e penúltimo corretos, o restante está trocado. \\
\hline P8: & Tem o último e penúltimo corretos, o restante está trocado. \\
\hline P9: & Correto. \\
\hline P10: & Errou na ordenação de um dos passos. \\
\hline P11: & Correto. \\
\hline
\end{tabular}

A Tabela 9 mostra os dados relativos à ordenação dos passos para enviar uma mensagem de correio eletrónico de acordo com a explicação do Tutorial 3, verificandose que $5 / 9$ dos participantes ordenaram corretamente os passos; $3 / 9$ dos participantes ordenaram corretamente o último e o penúltimo passos e $1 / 9$ dos participantes errou na ordenação de um dos passos.

Tabela 10 - Apresentação dos resultados de ordenação das tarefas realizadas pelos participantes para Conversar na Comunidade miOne

Tutorial 4-Como Conversar na Comunidade miOne
Tarefa: Ordenar de 1 a 5 os passos para enviar uma mensagem na comunidade miOne.
\begin{tabular}{|l|l|}
\hline Respostas \\
\hline P3: & Correto. \\
\hline P4: & Tem o último correto, o restante está trocado. \\
\hline P5: & Errou na ordenação de um dos passos. \\
\hline P6: & Correto. \\
\hline P7: & Tem o último correto, o restante está trocado. \\
\hline P8: & Tem o último correto, o restante está trocado. \\
\hline
\end{tabular}




\begin{tabular}{|l|l|}
\hline P9: & Correto. \\
\hline P10: & Errou na ordenação de um dos passos. \\
\hline P11: & Correto. \\
\hline
\end{tabular}

A Tabela 10 apresenta os resultados da ordenação dos passos para o Tutorial 4, constatando-se que 4/9 dos participantes ordenaram corretamente os passos; 3/9 dos participantes ordenaram corretamente o último passo e 2/9 dos participantes erraram na ordenação de um dos passos.

Pela análise das Tabelas 7, 8, 9 e 10 a tarefa de ordenação dos passos permitiu percecionar que, no geral os participantes tinham dificuldades em relembrarem-se dos primeiros passos mostrados nos tutoriais, pelo que a maior parte das vezes acertavam nos dois últimos passos. Este facto pode dever-se à diminuição da capacidade da memória de trabalho, que de acordo com Zheng et al (2012), apresenta o seu pico aos 45 anos de idade e começa a diminuir aos 50 anos de idade.

Considerando que a idade mínima dos participantes é de 64 anos de idade, sendo esse o único participante que acertou sempre na ordenação dos passos; 4/9 dos participantes acertaram na ordenação de apenas um tutorial; $1 / 9$ dos participantes acertou na ordenação de dois tutoriais; $1 / 9$ dos participantes errou na ordenação de todos os tutoriais e $2 / 9$ dos participantes acertaram na ordenação de três tutoriais.

Após a realização desta tarefa foram avaliadas as categorias vídeo, voz-off e música de fundo e respetivas subcategorias. As Tabelas 11, 12 e 13 apresentam sumariamente a análise dos resultados das perceções dos participantes, relativamente a essas categorias e subcategorias para todos os tutoriais realizados.

A Tabela 11 apresenta sumariamente as perceções dos participantes, relativamente à categoria vídeo e às suas subcategorias.

Tabela 11 - Categoria Vídeo, com as subcategorias Nitidez, Ritmo da Informação Visual e Equilíbrio entre a Narração e Vídeo

\begin{tabular}{|l|l|}
\hline $\begin{array}{l}\text { Subcategori } \\
\text { a }\end{array}$ & \begin{tabular}{l} 
Constatações das respostas dos participantes \\
\hline \multirow{5}{*}{ Nitidez }
\end{tabular} \\
& $\begin{array}{l}\text { De acordo com as respostas dadas pelos participantes pode-se constatar que as imagens de } \\
\text { todos tutoriais estavam nítidas. } \\
\text { Podendo-se verificar esse facto pela afirmação de P5, relativamente ao tutorial 1: } \\
\text { "Sim, para mim acho que sim. Estava bem explícito, está bem quer dizer, é fácil de } \\
\text { assimilar tudo o que está, é." } \\
\text { Ou a de P10 relativamente ao tutorial 4: } \\
\text { "A base da plataforma é muito legível, muito compreensível." }\end{array}$ \\
\hline
\end{tabular}




\begin{tabular}{|c|c|}
\hline $\begin{array}{l}\text { Ritmo da } \\
\text { Informação } \\
\text { Visual }\end{array}$ & $\begin{array}{l}\text { Considerando as respostas facultadas pelos participantes pode-se constatar que a } \\
\text { apresentação da informação visual estava num ritmo adequado, para utilizadores com } \\
\text { conhecimentos no uso do computador e da Internet. No entanto, em alguns participantes } \\
\text { denota-se alguma preocupação na rapidez dos tutoriais, para pessoas que não tivessem } \\
\text { facilidade no domínio dos computadores e da Internet. } \\
\text { Verificando-se esta preocupação pelo testemunho de P6, relativamente ao tutorial 1: } \\
\text { "Isto para quem tenha, digamos, uma certa, mais um bocado de agilidade, de mexer é } \\
\text { uma coisa. Agora para a grande maioria (...) isto é capaz de ser demasiado rápido, para } \\
\text { a grande maioria das pessoas." } \\
\text { Ou de P3 relativamente ao tutorial 3: } \\
\text { "Eu acho que para nós que estamos habituados não aparenta, não tem qualquer } \\
\text { dificuldade. Mas uma pessoa é capaz, aquela história do receber e depois apagar a } \\
\text { mensagem e depois recuperar a mensagem. Quer dizer não sei se com uma ... para } \\
\text { iniciante não é, está rápido. Agora para nós isto está perfeito." }\end{array}$ \\
\hline $\begin{array}{l}\text { Equilíbrio } \\
\text { da } \\
\text { Narração e } \\
\text { vídeo }\end{array}$ & $\begin{array}{l}\text { Segundo as considerações dos participantes, nota-se que a narração está de acordo com o } \\
\text { vídeo. } \\
\text { Como se pode verificar pela resposta de } \mathrm{P} 5 \text {, no tutorial 3: } \\
\text { "Acho que qualquer pessoa entende, está muito aceitável. É, está bem coordenado, uma } \\
\text { coisa com a outra está bem coordenado. Acho que sim." } \\
\text { Ou de P3 relativamente ao tutorial 4: } \\
\text { Sim, sim, sim, sim. E está bem feito. }\end{array}$ \\
\hline
\end{tabular}

Quanto à análise da categoria vídeo pode-se verificar que os entrevistados consideraram os tutoriais adequados e desenhados a pensar num possível utilizador da comunidade miOne. No entanto, ressalvase que para seniores que se estejam a iniciar no uso do computador e da Internet, os tutoriais estarão um pouco rápidos demais, dificultando a compreensão e posterior execução dos passos mostrados.

A Tabela 12 apresenta resumidamente as constatações relativas à categoria voz-off e respetivas subcategorias.

Tabela 12 - Voz-off, com as subcategorias Perceção Voz Masculina, Perceção Voz Feminina, Alternância de Vozes e Velocidade da Fala

\begin{tabular}{|c|c|}
\hline Subcategoria & Constatações das respostas dos participantes \\
\hline $\begin{array}{l}\text { Perceção Voz } \\
\text { Masculina }\end{array}$ & $\begin{array}{l}\text { Em todos os tutoriais avaliados constata-se na transcrição das respostas dadas pelos } \\
\text { participantes que a voz masculina é percetível. } \\
\text { Destacando-se as afirmações de P11 relativamente ao tutorial 1: } \\
\text { "Sim perfeitamente. Ai eu percebo perfeitamente. É uma voz clara." } \\
\text { E de P5 relativamente ao tutorial 3: } \\
\text { "Não ele é muito simpático, tem uma voz bonita (...) É uma voz muito... masculina, } \\
\text { mas nem forte de mais nem fraca. Está num tom muito agradável de ouvir." }\end{array}$ \\
\hline $\begin{array}{l}\text { Perceção Voz } \\
\text { Feminina }\end{array}$ & $\begin{array}{l}\text { Denota-se relativamente à "Perceção da Voz Feminina", que os participantes tiveram } \\
\text { dificuldades em aperceber-se da sua existência. Após serem questionados sobre ela é } \\
\text { que os participantes perceberam a sua existência. Depois de notarem a sua existência } \\
\text { consideraram-na percetível. } \\
\text { Verificando-se as seguintes afirmações de P9 relativamente ao tutorial 1: } \\
\text { "Percebo, até melhor." } \\
\text { E de P7 relativamente ao tutorial 3: } \\
\text { "Percebe-se perfeitamente." }\end{array}$ \\
\hline $\begin{array}{l}\text { Alternância de } \\
\text { Vozes }\end{array}$ & $\begin{array}{l}\text { Na subcategoria "Alternância de Vozes" verificou-se que depois dos participantes se } \\
\text { aperceberem da existência da voz feminina, conseguiram percecionar o porquê da sua } \\
\text { presença, referindo que devia ser para chamar a atenção ou fornecer informações } \\
\text { adicionais. }\end{array}$ \\
\hline
\end{tabular}




\begin{tabular}{|l|l|}
\hline & $\begin{array}{l}\text { Como se pode constatar pelas transcrições de conteúdo das respostas de P9 } \\
\text { relativamente ao tutorial 1: } \\
\text { "Não sei para dar realce àquilo de poder esconder a senha, por ser uma coisa } \\
\text { diferente, para chamar a atenção desse pormenor. Uma alteração de voz para dar } \\
\text { realce apenas." } \\
\text { E de P3 relativamente ao tutorial 3: } \\
\text { "Foi informaçóes adicionais, coisas que se poderia fazer." }\end{array}$ \\
\hline A "Velocidade da Fala" é considerada adequada. No tutorial 1, um dos participantes \\
alerta que esta pode estar um pouco acelerada para quem se esteja a iniciar no uso do \\
computador e da Internet e outro refere que esta pode estar lenta para quem já utiliza o \\
Falocidade da da \\
computador e Internet. \\
$\begin{array}{l}\text { Este facto nota-se pela afirmação de P7 relativamente ao tutorial 1: } \\
\text { "Quer dizer para quem se calhar está a iniciar o registo, a fazer a primeira vez é } \\
\text { capaz de ser (...), para mim não. Consegui acompanhar. Agora para outras pessoas } \\
\text { seria os passos (...)". } \\
\text { E de P9 relativamente ao tutorial 1: } \\
\text { "Está, está. Vou partir do princípio que são pessoas que não têm domínio total da } \\
\text { internet, quem tiver um domínio total da internet, se calhar está um bocadinho lento. } \\
\text { Mas acho que se calhar para quem está a começar tem que ser assim." }\end{array}$ \\
\hline
\end{tabular}

Relativamente à categoria voz-off através da transcrição do conteúdo das respostas dadas pelos participantes pode-se compreender que as vozes masculina e feminina são percetíveis, bem como a velocidade da fala é adequada. Quanto à alternância entre voz masculina e feminina, apesar dos participantes não constatarem imediatamente a presença da voz feminina, quando a notavam percecionavam que esta existia para referir informações opcionais/adicionais.

A Tabela 13 resume as perceções dos participantes quanto à categoria música de fundo e respetivas subcategorias.

Tabela 13 - Categoria Música de Fundo, com as subcategorias Perceção Música de Fundo e Compreensão das Vozes

\begin{tabular}{|l|l|}
\hline Subcategoria & Constatações das respostas dos participantes \\
\hline & Analisando as transcrições do conteúdo das respostas dadas pelos inquiridos nota-se \\
que a música de fundo é percetível. \\
Como se pode verificar pelo testemunho de P9 relativamente ao tutorial 1: \\
"Notei. E é agradável." \\
E de P11 relativamente ao tutorial 2: \\
"Gostei muito." \\
$\begin{array}{l}\text { Músiceção de } \\
\text { Fundo }\end{array}$ & $\begin{array}{l}\text { No entanto, é importante ressalvar que para 2/9 dos participantes que a música de } \\
\text { fundo era repetitiva, donde se destaca as afirmações: }\end{array}$ \\
& $\begin{array}{l}\text { "Sim. É, mas é um bocado repetitiva. (...) Repetitiva e a apresentação está um bocado } \\
\text { longa, portanto torna-se mais notada. Estava bem se fosse a apresentação de uma } \\
\text { página, mas isto são várias páginas, é sempre a mesma." }\end{array}$ \\
& $\begin{array}{l}\text { P5 relativamente ao tutorial 2: } \\
\text { "Acho que a música quanto mais melodiosa for mais agarra, o espetador (...) um } \\
\text { bocadinho como diz aqui a amiga repetitiva. Cansativa. Eu diria que até para aqui } \\
\text { este tipo de música de relaxe, lindíssimas e é sempre diferente e sempre naquele tom }\end{array}$ \\
\hline
\end{tabular}




\begin{tabular}{|l|l|}
\hline & $\begin{array}{l}\text { de relaxe, que é lindas. (...) Música que saiba bem ao ouvido, suave, que atrai ficar ali } \\
\text { às vezes só por causa da música. Ficar a ouvir e a ver. Mas a música tem de facto um } \\
\text { grande relevo." }\end{array}$ \\
\hline $\begin{array}{l}\text { Apesar de, na subcategoria anterior, os participantes terem relatado o fato de } \\
\text { percecionarem a música de fundo, na subcategoria compreensão das vozes referem que } \\
\text { esta não perturba o entendimento da narração. Constando-se este facto pelas seguintes } \\
\text { asserções: }\end{array}$ \\
$\begin{array}{l}\text { P10 relativamente ao tutorial 1: } \\
\text { das Vozes }\end{array}$ \\
$\begin{array}{l}\text { "Não. (...) Pelo contrário. Desde que esteja nos níveis adequados. É mais apelativo neste tom assim adequado." } \\
\text { tem é }\end{array}$ \\
$\begin{array}{l}\text { P6 relativamente ao tutorial 3: } \\
\text { "Não, não. Não, não perturba. Compreende-se perfeitamente." }\end{array}$
\end{tabular}

$\mathrm{Na}$ categoria música de fundo verificouse que os participantes notaram a música de fundo, mas consideram que esta não perturbou na compreensão das vozes.

As entrevistas realizadas permitiram verificar se os tutoriais produzidos, seguindo as recomendações recolhidas na fase de revisão de literatura, eram percetíveis para os seniores.

Pela leitura das Tabelas 11, 12 e 13 os dados obtidos através desta avaliação, permitiram verificar que a utilização de algumas das recomendações bibliográficas, possibilitaram a perceção dos tutoriais pelos participantes. Neste contexto e de acordo com Fisk et al (2009) e Czaja \& Sharit (2012) deve-se evitar o uso de música de fundo durante o tempo de discurso, pelo que esta foi mantida sempre no mesmo nível para que fosse audível em momentos de silêncio da narração. Os autores Fisk et al (2009), referem que devem-se efetuar as pausas de discurso necessárias, tendo as vozes-off seguido essa recomendação. Ainda neste contexto os autores Czaja \& Sharit (2012) mencionam que é importante aliar ao vídeo a narração, notando-se na avaliação que os participantes consideraram a existência de equilíbrio entre a narração e vídeo. No entanto, alguns dos participantes alertaram para o facto que para iniciantes do uso do computador e da Internet que estes poderiam estar um pouco acelerados, mas que no seu contexto de utilizadores diários que estes estariam num ritmo adequado. De acordo com Czaja \& Sharit (2012), o narrador deve adotar um estilo informal, sem o uso de termos técnicos e providenciar uma voz amiga, para que o idoso se sinta mais confortável. Tendo por base esta recomendação a conceção do guião de vozoff para cada um dos tutoriais, foi realizada sem recorrer ao uso de vocabulário complexo e foram utilizados termos presentes na comunidade miOne.

De acordo com estes dados pode-se verificar que no geral os vídeos tutoriais cumprem com os requisitos relativos às categorias vídeo, voz-off e música de fundo

\section{Considerações Finais}

A realização e avaliação dos tutoriais, permitiu analisar a importância que estes poderiam ter na comunidade miOne, bem como se estes estariam adaptados ao seu público-alvo: os idosos.

Analisando as respostas obtidas nas entrevistas perceciona-se que os tutoriais no geral foram concebidos de acordo com o idoso e futuro utilizador da comunidade miOne. No entanto não se pode afirmar que estes seriam um meio facilitador da aprendizagem, por não ter sido possível avaliar essa componente no tempo disponível para a investigação. 
Os tutoriais foram construídos tendo por base características referidas na bibliografia consultada, podendo-se referir que a realização de tutoriais audiovisuais para a população idosa, no contexto da comunidade miOne deverão ter as especificidades referidas por Czaja \& Sharit (2012) e Fisk et al (2009):

- Narração pausada, com uma linguagem informal (vocabulário simples e sem jargão técnico);

- Predominantemente utilizar a vOz masculina e a voz feminina, apenas para a captação da atenção;

- Música de fundo, preferencialmente instrumental e num nível apenas audível em momentos de silêncio do narrador;

- Minimizar ruídos de fundo e eco;

- Evitar fontes decorativas (recomendação para os créditos);

- Utilizar contrastes de 50:1 (fundo branco e letras pretas ou vice-versa) (recomendação para os créditos);

- Simultaneamente aliar narração e vídeo numa apresentação segmentada.

O objetivo foi alcançado através da realização de quatro tutoriais audiovisuais adaptados ao idoso, para o uso da comunidade miOne.

É importante referir que o presente estudo incentiva a que mais tutoriais vocacionados para a população idosa possam ser concebidos, pelo facto de estarem presentes as indicações relevantes para a sua conceção. Sugere-se que outros estudos, que se proponham realizar tutoriais relativos à comunidade miOne, ou relacionados com outras plataformas úteis para os idosos, avaliem a utilidade destes como meio para a sua aprendizagem.

\section{Agradecimentos}

Agradece-se à direção da Universidade Sénior Florbela Espanca em Matosinhos por acolher esta investigação e aos idosos participantes pela sua disponibilidade e simpatia. Um agradecimento muito especial, à Olinda e ao Paulo, pelos seus sábios conselhos. Agradece-se também à Ana Rita Almeida e ao Cláudio Duarte, que deram voz aos tutoriais, pelo trabalho de qualidade, disponibilidade e simpatia.

Agradece-se ainda à equipa do projeto SEDUCE pelo auxílio prestado na construção dos tutoriais. Esta investigação foi desenvolvida no âmbito do projeto SEDUCE, financiado pela Fundação para a Ciência e Tecnologia e co-financiado pelo Programa Operacional Temático Factores de Competitividade (FCTPTDC/CCI/COM/111711/2009 e COMPETE-FCOMP-01-0124-FEDER014337).

\section{Bibliografía}

1. T.-. (2002). Requisitos Ergonômicos para Trabalho de Escritórios ABNT, A. B. d. N. com Computadores Parte 11 - Orientações sobre Usabilidade. In A. A. B. d. N. Técnicas (Ed.). Brasil: ABNT - Associação Brasileira de Normas Técnicas.

2. Aiken, L. (1995). Aging: An Introduction to Gerontology: Thousands Oaks: SAGE Publications, Inc.

3. Czaja, S., \& Sharit, J. (2012). Designing Training and Instructional Programs for Older Adults: CRC Press. 
4. Coutinho, C. (2011). Metodologia de Investigação em Ciências Sociais e Humanas: teoria e prática. Coimbra: Edições Almedina. 5. Dumas, J., \& Redish, J. (1999). A Practical Guide to Usability Testing. United Kingdom: Intellect Ltd.

6. Ferreira, S. (2013 Tecnologias de informação e comunicação e o cidadão sénior: estudo sobre o impacto em variáveis psicossociais e a conceptualização de serviços com e para o cidadão sénior. (Doutoramento em Informação e Comunicação em Plataformas Digitais) Universidade de Aveiro, Aveiro.

7. Ferreira, A. (2008). Usabilidade e Acessibilidade no design para a Web. (Mestrado), Universidade do Porto, Porto.

8. Fisk, A., Rogers, W., Charness, N., Czaja, S., \& Sharit, J. (2009). Designing for older adults Principles and Creative Human factors Approaches: CRC Press.

9. Fonseca, A. (2005). Desenvolvimento humano e envelhecimento: ClimepsiI Editores.

10. Giannakouris, K. (2010). Population and social conditions: Eurostat.

11. Gray, D. (2009). Doing Research in the Real World: SAGE.

12. Henry, S. (2007). Just Ask: Integrating Accessibility Throughout Design. Madison, WI:ET
13. INE. (2009). Projeções de População Residente em Portugal 2008 - 2060: Instituto Nacional de Estatística. Retrieved 8/12/2013 from http://goo.gl/aBhjGl

14. INE. (2012). Inquérito à Utilização de Tecnologias da Informação e da Comunicação pelas Famílias - 2012: Instituto Nacional de Estatística.

15. Nielsen, J. (1993). Usability Engineering. San Diego: Academic Press.

16. Nielsen, J. (2012). Usability 101: Introduction to Usability. Retrieved 06/10/2014, 2014, from http://goo.gl/ Arj8ku

17. Nini, P. (2006). Typography and the Aging Eye: Typeface Legibility for Older Viewers with Vision Problems. Retrieved 8/3/2014, from http://goo.gl/7AvtCy

18. OMS. (S.d.). Definition of an older or elderly person. Retrieved 29/11/2014, from Organização Mundial de Saúde http://goo.gl/LZ2pQD

19. Paúl, C. (2005). Envelhecimento ativo e redes de suporte social. Sociologia

20. Pires, A. (2008). Efeitos dos Videojogos nas Funções Cognitivas da Pessoa Idosa. Faculdade de Medicina da Universidade do Porto.

21. PORDATA, \& INE. (2014). Esperança de vida à nascença. Retrieved 17/10/2014, from PORDATA http://goo.gl/U2otoQ 
22. PORDATA. (2014). Indicadores de fecundidade: Índice sintético de fecundidade e taxa bruta de reprodução. Retrieved 10/11/2014, from http://goo.gl/JhYc2Z

23. PORDATA. (2013). População residente, estimativas a 31 de Dezembro: total e por grupo etário. Retrieved 8/12/2013, from http://goo.gl/O0kUWA

24. Redish, J., \& Chisnell, D. (2004). Designing Web Sites for Older Adults: A Review of Recent Research. Washington: AARP.

25. Ribeiro, O. \& Paúl, C. (2011) Manual de Envelhecimento Activo. Lidel Editores

26. Rosa, B. (2012). Sénior, o Turista do Futuro. (Mestrado em Turismo,
Especialização em Gestão Estratégica de Destinos Turísticos), Escola Superior de Hotelaria e Turismo do Estoril, Estoril.

27. Rosa, M. J. (2012). O Envelhecimento da Sociedade Portuguesa: Relógio D'Água Editores.

28. UNFPA, \& International, H. (2012). Ageing in the Twenty-First Century. Retrieved 29/11/2013, from UNFPA and HelpAge International http://goo.gl/ Fz8jGZ

29. UPA. (S.d) What is Usability?, Retrieved 24/02/2014 from http://goo.gl/eETsgP

30. Zheng, R., Hill, R., \& Gardner, M. (2012). Engaging Older Adults with Modern Technology: IGI Global.. 